http://jmscr.igmpublication.org/home/ ISSN (e)-2347-176x ISSN (p) 2455-0450

crossref DOI: https://dx.doi.org/10.18535/jmscr/v8i1.45

Journal Of Medical Science And Clinical Research

\title{
Benign Lesions of the Maxillary Sinus by Endoscopic Pre Lacrimal Maxillectomy versus Caldwell-Luc Approach- A Comparative Study
}

Authors

\section{Kalyani Hanumanthu ${ }^{1}$, G.Raghunadha Babu², B.Sudha ${ }^{3^{*}}$, Peri Sreekavya ${ }^{4}$}

${ }^{1}$ Postgraduate, Department of Otorhinolaryngology and Head and Neck Surgery, Govt. ENT Hospital,

Andhra Medical College, Visakhapatnam, Andhra Pradesh, India

${ }^{2}$ Professor and Head of the Department, Department of Otorhinolaryngology and Head and Neck Surgery,

Govt. ENT Hospital, Andhra Medical College, Visakhapatnam, Andhra Pradesh, India

${ }^{3}$ Assistant Professor, Department of Otorhinolaryngology, and Head and Neck Surgery, Govt. ENT

Hospital, Andhra Medical College, Visakhapatnam, Andhra Pradesh, India

${ }^{4}$ Postgraduate, Department of Otorhinolaryngology and Head and Neck Surgery, Govt. ENT Hospital,

Andhra Medical College, Visakhapatnam, Andhra Pradesh, India

*Corresponding Author

\section{B.Sudha}

\begin{abstract}
Background: The study aims to compare EPMM with conventional CLA to remove benign lesions of the maxillary sinus and to evaluate the usefulness of these approaches.

Patients and Methods: A total of 24 patients of which eight patients diagnosis of antrochoanal polyps recurrent cases, 4 are inverted papilloma, 8 are maxillary Naso alveolar cysts, 1 is an oroantral fistula, 2 with maxillary osteoma and 1 with the maxillary fibroma. These cases divided into two groups: group 1 included eight patients who underwent surgery with endoscopic prelacrimalmaxillectomy approach (EPMMA) group 2 underwent surgery by the Caldwell-Luc approach(CLA). They were followed up for six months. Surgical complications and recurrence were evaluated.

Results: The most common symptoms were nasal obstruction (66.6\%), rhinorrhea (54\%), headache (25\%), hyposmia (20.8\%). The study found that postoperative complications varied between both groups. Recurrence was seen in the EPMMA group is $66.6 \%$ and $0 \%$ in the CLA group.

Conclusion: EPMM is a useful approach for benign lesions of the entire wall of the maxillary sinus. The facial numbness after surgery was significantly shorter in EPMMA than that of CLA. The recurrence rate is less in CLA when compared to EPMMA.

Keywords: Recurrent antrochoanal polyp, maxillary osteomas, inverted papilloma,naso alveolar cysts, pre lacrimal, Caldwell Luc.
\end{abstract}

\section{Introduction}

Endoscopic sinus surgery has been used widely for the majority of thesinonasal diseases, including that in the maxillary sinus, various conditions of maxillary sinus include chronic sinusitis, odontogenic infections, and neoplastic conditions. In cases with sinus mucosal inflammation or infection, functional endoscopic sinus surgery reestablishes the ventilation and mucociliary clearance of the sinuses ${ }^{(2)}$. 
Antrachoanal polyp is one of the common pathologies of the paranasal sinus region that usually takes origin from the maxillary sinus (MS) extending into the nasopharynx through the choana. The treatment of antrochoanal polyp is mainly surgical, and endoscopic middle meatalantrostomy (EMMA) has become a widely accepted modality. In olden days open surgical techniques are used to provide better visualization of the MS and to prevent recurrence after simple resection. The canine fossa approach, CaldwellLuc procedure, and inferior meatalnasoantral window with resection of the anterior part of the inferior turbinate, are examples of traditional open techniques. However, many complications were observed after traditional open methods such as the cheek swelling in the immediate or late postoperative period, anesthesia problems, and numbness of the cheek. ESS with middle meatalantrostomy has been the most acceptable approach in the treatment of antrochoanal polyp. This approach is a minimally invasive and effective method, provides complete removal with some complications. Some authors have mentioned that EMMA alone cannot be sufficient due to its inaccessibility to the stalk located in the MS wall and narrow intranasal structures.

In cases of inverted papilloma, resection of its attachment sitehas been performed through a mucoperiosteal flap elevation surrounding the lesion with macroscopic safe margins. Incomplete removal of the lesion can lead to early tumor recurrence $^{(3)}$ by EMMA method because of the inaccessibility of the instrument in particular when the lesionis located anterior or inferior side of the maxillary sinus wall, it usually hard to remove through the natural ostium, in Such cases removal can be done by using the traditional Caldwell-Luc approach (CLA) or by way of a canine fossa puncture. Zhou et al. ${ }^{(5)}$ proposed the intranasal endoscopic prelacrimal recess approach to the maxillary sinus. This procedure includes removal of the medial wall of the prelacrimal recess with inferior turbinate and nasolacrimal duct preservation. Many cases have been described in the literature using this approach to remove any unilateral sinus diseases like inverted papilloma and chronic inflammation, the tumor of the pterygopalatine fossa, and tumor located at the infratemporal fossa. The Endoscopic prelacrimal medial maxillectomy (EPMM) approach has the advantage of avoiding an external scar.

\section{Aims and Objectives}

The study aims to compare EPMM with conventional CLA to remove benign lesions of the maxillary sinus and to evaluate the usefulness of these approaches based on our experience.

\section{Objectives}

1. Recurrence of the tumor

2. Post-operative complications

3. Duration of surgery

\section{Materials and Methods}

This retrospective study was performed in Otorhinolaryngology Department, Andhra medical college New Visakhapatnam, India, on 24 patients of 8 patients diagnosis of antrochoanal polyps recurrent cases, 4 are inverted papilloma, 8 are maxillary Naso alveolar cysts, 1 is an oroantral fistula, 2 with maxillary osteoma and 1 with the maxillary fibroma. These cases divided into two groups: group 1 included eight patients who underwent surgery with endoscopic prelacrimal maxillectomy approach (EPMMA) group 2 underwent surgery by the Caldwell-Luc approach (CLA). This study was conducted for a period of two years, six monthsvfrom January 2017 to June 2019, including the follow-up period from 3-6 months.

The study was performed after been approved by the local ethical committee, and written informed consent was taken from the patients for their clinical records used in this study.

All clinical parameters of the study subjects in the EPMMA group were compared with those of the CLA group. Patients from both groups had their preoperative CT scans graded according to the Lund-Mackay CT grading system. The operative 


\section{JMSCR Vol||08||Issue||01||Page 313-320||January}

findings and postoperative pathologic diagnoses were recorded. The postoperative status, including possible complications and disease recurrences, was also recorded.

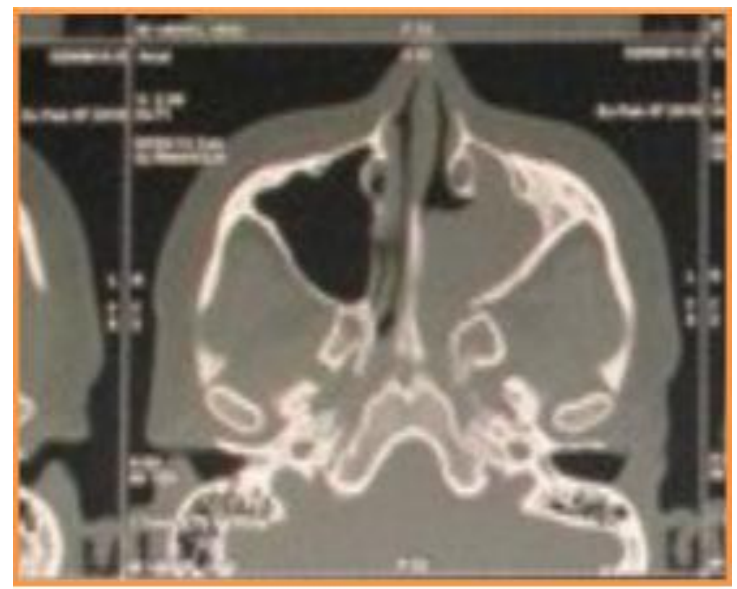

Figure 1 Axial section of recurrent antrochoanal polyp left side

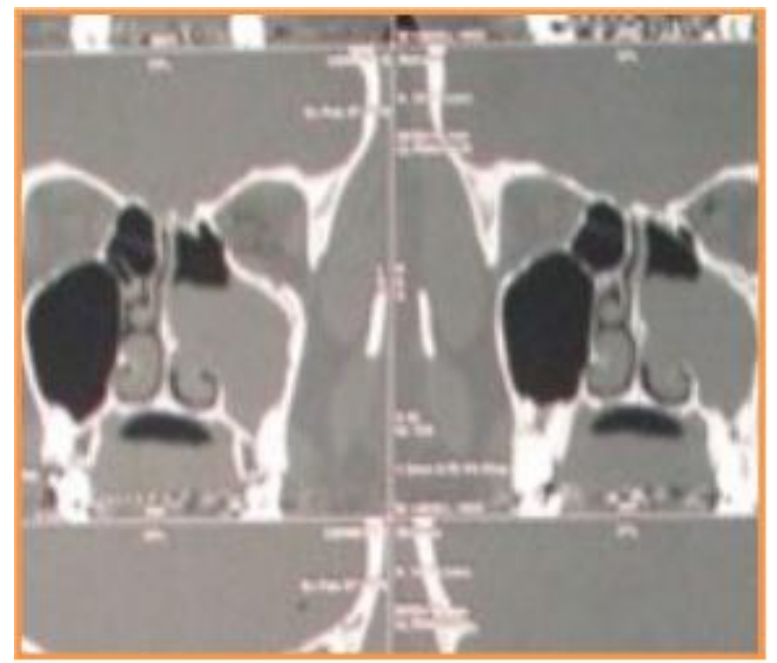

Figure 2 Coronal section of recjurrent antrochoanal polyp left side

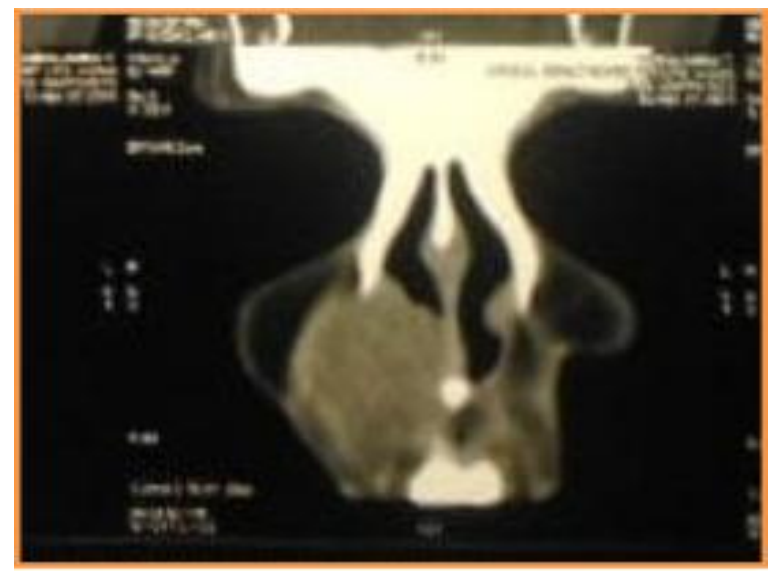

Figure 3 Axial section of fibrous osteoma right maxillary sinus

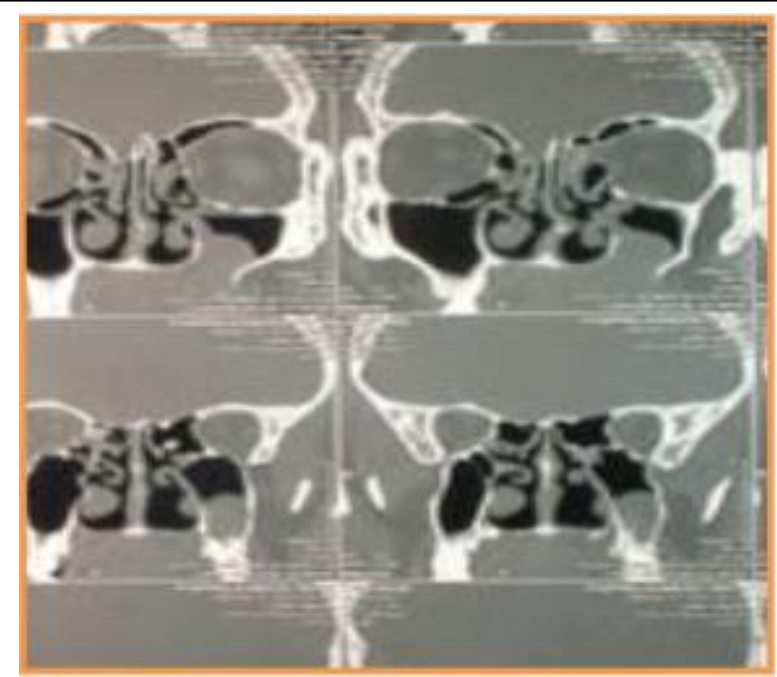

Figure 4 Coronal section of fibrous osteoma right maxillary sinus

\section{Surgical technique for EPMM}

The incision site was infiltrated with $1 \%$ lidocaine with 1:100,000 adrenaline solution. A curved mucosal incision on the lateral nasal wall was given between the inferior turbinate anterior aspect and the edge of the pyriform aperture till the bone. The sub periosteal mucosal flap was elevated posteriorly till the insertion of the inferior turbinate, and then the bony attachment of IT was disconnected. The inferior bony orifice of NLD could be seen after the mucoperiosteum was elevated posteriorly. The anterior bony part of the medial wall of the maxillary sinus (part of the maxillary, frontal process) was chiseled off,and after chiseling the bone posteriorly, the NLD was exposed, and the IT-NLD flap was formed, pushed medially and the anteromedial wall of the maxillary sinus was exposed. The maxillary sinus was then entered via the antrostomy made at the prelacrimal recess. When the antrostomy was adequately enlarged, the maxillary sinus was exposed widely, and all pathological tissues were removed under direct visualization. The IT-NLD mucosal flap was then repositioned, and the incision was sutured. 


\section{JMSCR Vol||08||Issue||01||Page 313-320||January}

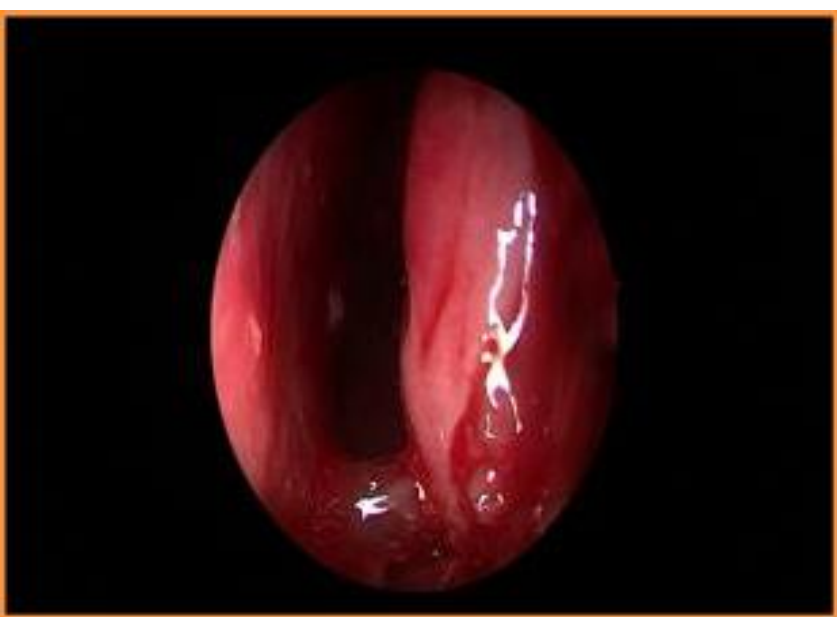

Figure 5 Mucosal incision of the nose at the anterior margin of inferior turbinate at the inferior turbinate anterior margin

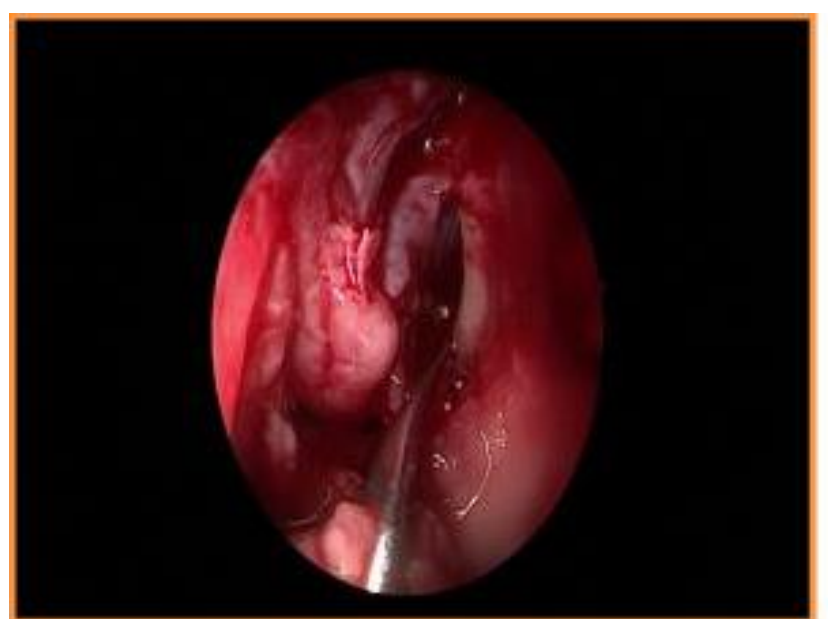

Figure 6 Lateral wall of the mucosa elevated posteriorly

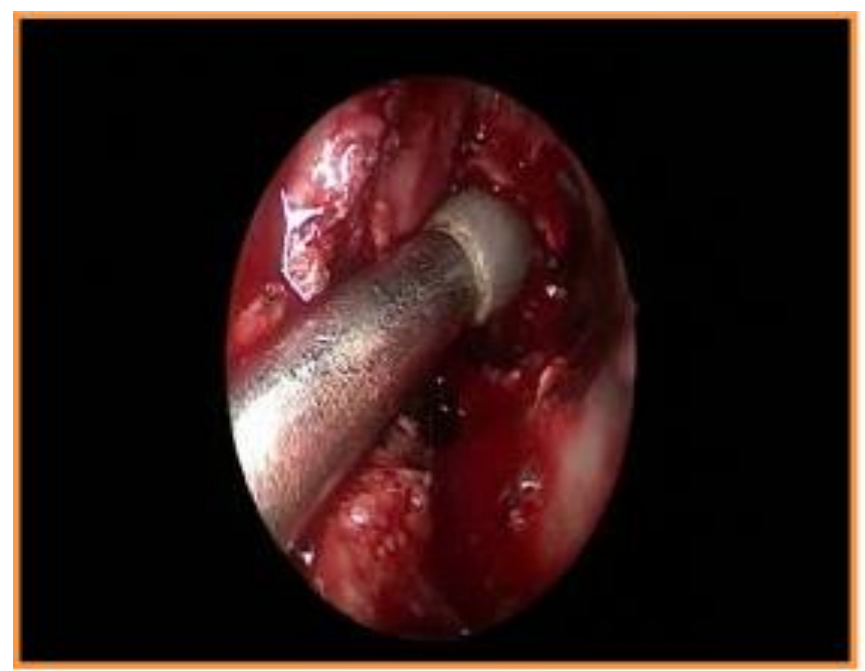

Figure 7 Drilling of the medial wall in the pre lacrimal region

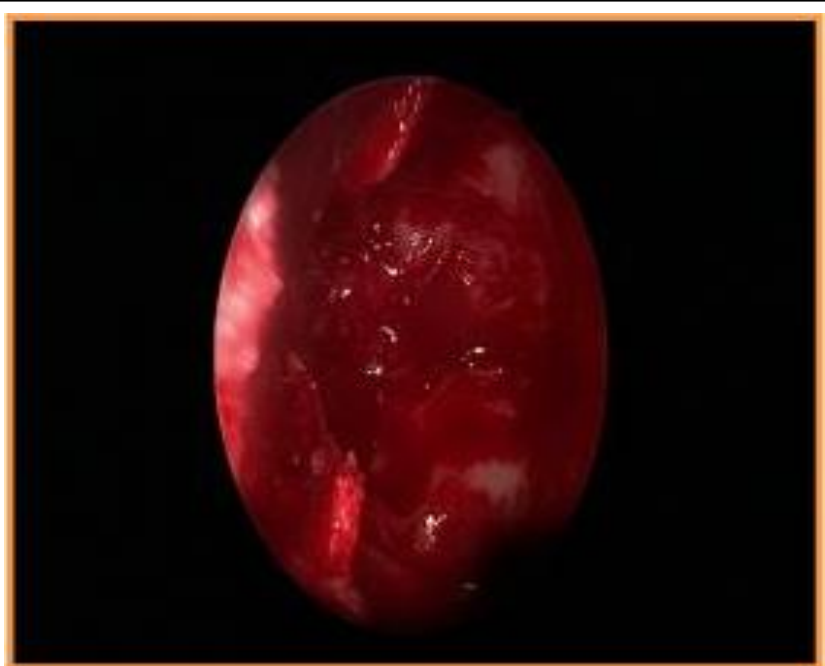

Figure 8 Complete exposure of the maxillary sinus

\section{Surgical technique for CLA}

The procedure was done either under general anesthesia or local anesthesia. The upper lip is retracted, and the tissues just above the gingivolabial reflection were infiltrated with $1 \mathrm{ml}$ 1:200 000 solutions of adrenaline or mixed with $1 \%$ xylocaine in cases of local anesthesia. An incision was made in the upper gingivobuccal sulcus leaving a cuff of mucosa for reapproximation on the dental side of the incision. An incision was made through the periosteum using a unipolar cautery, and a periosteal elevator was used to elevate superiorly, medial elevation till the piriform aperture and lateral extension to the lateral wall of the maxilla was performed. As the periosteumwas elevated superiorly, the infraorbital nerve bundle was identified. Entry into the maxillary sinus was performed with a 2$\mathrm{mm}$ osteotome and a mallet in the canine fossa. Suturing the sublabial incision was done using chromic catgut with a good approximation of edges. Postoperative antibiotics were given in all cases for a minimum of 5 days with an analgesic. $^{(1)}$ 


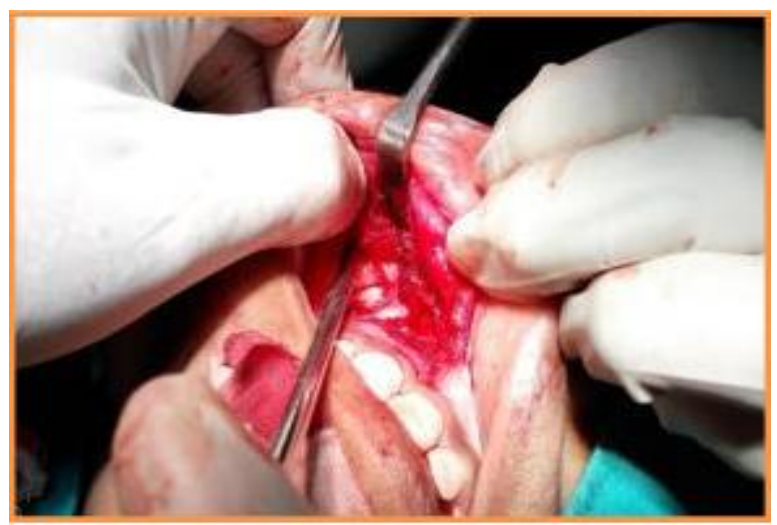

Figure 9 Maxillary sinus opening by cald well approach

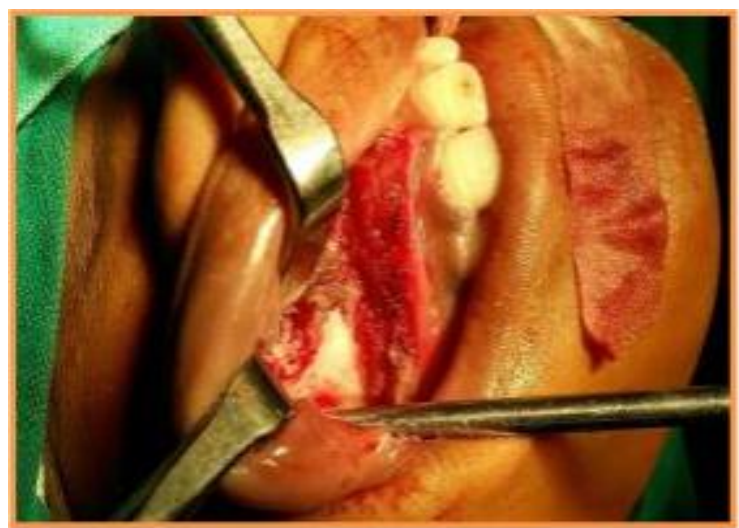

Figure 10 Exposure of fibroma in the maxillary sinus

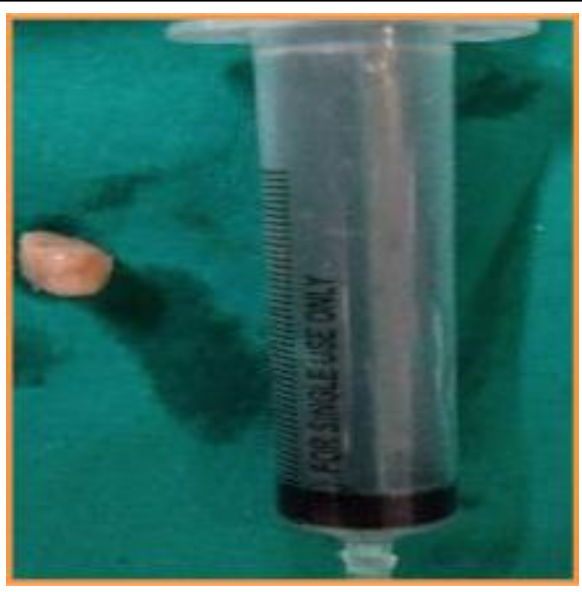

Figure 11 Excised fibroma specimen

\section{Observation and Results}

The study included 24 patients with recurrent antrochoanal polyps, maxillary Naso alveolar cysts, inverted papillomas, oroantral fistula, maxillary osteoma, and maxillary fibroma

All of them wereclassified into two groups: group 1 included 12 patients who underwent EPMMA, and group 2 included 12 patients who underwent surgery using aCLA.

The demographic characteristics of the patients were shown in Tables 1-4.

Table 1. Demographic data of our patients Group

\begin{tabular}{|l|c|c|c|}
\hline Demography & $\begin{array}{c}\text { Group 1: EPMMA group } \\
{[\mathrm{n}(\%)]}\end{array}$ & $\begin{array}{c}\text { Group 2: CLA group [n } \\
(\%)]\end{array}$ & Total (n=17) [n (\%)] \\
\hline Sex & & & \\
\hline Males & $8(66.6 \%)$ & $5(41.66 \%)$ & $13(54.16 \%)$ \\
\hline Females & $4(33.33 \%)$ & $7(58.33 \%)$ & $11(45.83 \%)$ \\
\hline Total & $12(50 \%)$ & $12(50 \%)$ & $24(100 \%)$ \\
\hline Age (years) & & & $17-56$ \\
\hline Range & $17-56 \mathrm{yrs}$ & $20-55 \mathrm{yrs}$ & \\
\hline
\end{tabular}

EPMMA - endoscopic prelacrimal medial maxillectomy

CLA -Cladwell-luc approach.

Table 2 Disease characteristics in the studied groups

\begin{tabular}{|l|c|c|c|}
\hline & $\begin{array}{c}\text { Group 1: EPMMA group } \\
{[\mathrm{n}(\%)]}\end{array}$ & $\begin{array}{c}\text { Group 2: CLA group [n } \\
(\%)]\end{array}$ & $\begin{array}{c}\text { Total }(\mathrm{n}=17) \text { [n } \\
(\%)]\end{array}$ \\
\hline Laterality & & & $14(58.3 \%)$ \\
\hline Right sided & $9(75 \%)$ & $5(41.6 \%)$ & $10(41.6 \%)$ \\
\hline Left sided & $3(25 \%)$ & $7(58.3 \%)$ & \\
\hline Signs and symptoms & & & $16(66.6 \%)$ \\
\hline Nasal obstruction & $12(100 \%)$ & $4(33.3 \%)$ & $13(54 \%)$ \\
\hline Rhinorrhea & $12(100 \%)$ & $1(8.33 \%)$ & $6(25 \%)$ \\
\hline Headache & $4(33.3 \%)$ & $2(16.6 \%)$ & $5(20.8 \%)$ \\
\hline Hyposomia & $5(41.6 \%)$ & $0(0 \%)$ & $8(33.3 \%)$ \\
\hline MS polyp protrusion & $8(66.6 \%)$ & $0(0 \%)$ & $9(37.5 \%)$ \\
\hline Recurrent cases & $8(66.6 \%)$ & $1(8.33 \%)$ &
\end{tabular}

EPMMA - endoscopic prelacrimal medial maxillectomy

CLA - Cladwell-luc approach. 
Table 3. Operative time

\begin{tabular}{|l|c|c|}
\hline Operation time(min) & EPMMA group [n (\%)] & CLA group [n (\%)] \\
\hline Range & $50-60$ & $65-75$ \\
\hline
\end{tabular}

Table 4 Postoperative complications between two groups

\begin{tabular}{|l|c|c|c|}
\hline Postoperative complications & $\begin{array}{c}\text { Group 1: EPMMA } \\
\text { group [n (\%)] }\end{array}$ & $\begin{array}{c}\text { Group 2: CLA group } \\
{[\mathrm{n}(\%)]}\end{array}$ & $\begin{array}{c}\text { Total }(\mathrm{n}=17) \\
{[\mathrm{n}(\%)]}\end{array}$ \\
\hline Bleeding & $12(100 \%)$ & $12(100 \%)$ & $24(100 \%)$ \\
\hline Nasolacrimal duct injury & $0(0 \%)$ & $0(0 \%)$ & $0(0 \%)$ \\
\hline Postoperative lacrimation & $0(0 \%)$ & $1(8.33 \%)$ & $1(4.16 \%)$ \\
\hline Synechia formation & $6(50 \%)$ & $0(0 \%)$ & $5(20.83 \%)$ \\
\hline Recurrence & $2(16.6 \%)$ & $0(0 \%)$ & $2(8.33 \%)$ \\
\hline Swelling of cheek & $2(16.6 \%)$ & $10(83.3 \%)$ & $12(50 \%)$ \\
\hline Numbness of cheek & $2(16.6 \%)$ & $7(58.3 \%)$ & $9(37.5 \%)$ \\
\hline
\end{tabular}

EPMMA, endoscopic prelacrimal medial maxillectomy; CLA Cladwell-Luc approach

\section{Discussion}

Endoscopic sinus surgery has been frequently performed for sinonasal disease, and middle meatalantrostomy is the most basic technique in the surgical procedure. In this study, we focused on benign lesions of the maxillary sinus by using EPMM as described initially by Zhou et al.In many cases of inflammation or infectious diseases likeodontogenic, fungal or chronic sinusitis, and nasal polyposis, the attached mucosa with a free margin was not removed usually as the purpose was to reestablish ventilation, mucociliary clearance of the sinuses with the removal of irreversibly changed tissue. Therefore, it would be better to confine the study population to tumorous lesions to assess a suitable surgical procedure for maxillary sinus disease. The cases of malignancy were excluded because an external approach should be considered when there is a bony invasion. Finally, we reviewed 24 patients who needed a new surgical procedure for benign maxillary sinus tumor removal, and among these patients, 12 patients underwent surgery through EPMM.

There are many types of benign tumors originating from the sinonasal cavity, including inverted papilloma, antrochoanal polyps, osteomas, cysts, hemangioma, fibrous dysplasia, and angiofibroma. Of these, antrochoanal polyps, cysts, and inverted papilloma, which accounted for most of our study population, have a high recurrence rate and a chance of malignant transformation in inverted papilloma. These tumors are well known to their centrifugal growth pattern. Even though such a tumor occupies the nasal cavity with large volumes, usually, the origin is often located in a focal area. Therefore, it is essential to predict the attachment site of the through preoperative radiological imaging, and the tumor must be removed entirely around the attachment site. Lee et al. reported that focal hyperostosis on CT is taken asa predictor of inverted papilloma origin. In our study population, $37.5 \%$ of all patients had a previous history of surgery.

In most cases, whereonly middle meatalantrostomy was performed as primary surgery, the lesions could not be removed from the origin site attachment properly.

Because of the characteristic anatomy of the maxillary sinus, the inferior and anterior walls of the maxillary sinus are challenging to approach even with angled endoscopes andmicrodebrider. In literature,the difficult-to-approach area of the maxillary sinus was accessed through the CLA and EPMMA as even the experienced sinus surgeon can have trouble accessing all walls of the maxillary sinus

In 2007, Zhou et al. ${ }^{(5)}$ first reported operating using EPMM for maxillary sinus disease. Followed by many surgeons have reported cases using this approach. However, the comparison between CLA and EPMM, the indications and limitations of both are also not well established. In 
our experience, there are two advantages of using EPMM; one is to avoid nasolacrimal duct injury while opening a lacrimal bone surrounding a nasolacrimal duct, and the second is to facilitate instrumentation by removing the medial wall of the prelacrimal recess widely.

EPMM is performed by removing the medial wall of the prelacrimal recess, the bone between the nasolacrimal duct and the pyriform aperture. Bony removal of medial maxillary sinus wall to the natural ostium, the anterior margin of the middle meatalantrostomyis done after full exposure of the nasolacrimal duct, and medialization with lateral nasal wall mucosa can be done. This results in the wide surgical field, making it easier to use the instruments in cases of widely attached maxillary sinus tumors.

In thepresent study, three patients of the EPMM group (16.6\%) had facial paraesthesias surrounding the cheek and upper lip area postoperatively. Although our study showed a significant difference in the incidence of facial paraesthesias between the two groups, the duration was significantly shorter with EPMM than with CLA. These neurologic complications are caused by injuries to the branches of the infraorbital nerve, mainly the anterior superior alveolar nerve and the middle superior alveolar nerveless commonly. Nerve damage can occur while drilling over the pyriform aperture. Nerve transection merely happens during the EPMM, and transient numbness ${ }^{(7)}$ occurred because of thermal injury by cauterization or drilling. However, when making an antral window in CLA when elevating periosteumtill the infraorbital canal, the main branch of the infraorbital nerve could be at risk. Cauterization over the injured infraorbital artery could also do permanent damage to the infraorbital nerve.

EPMM has the advantage of reducing complications by preserving the inferior turbinate and lacrimal duct when compared with endoscopic medial maxillectomy to a transnasal surgical approach.Osguthorpe and Weisman ${ }^{(6)}$ had performed medial maxillectomy in 35 patients and reported that all patients complained of nasal crusting as a symptom of empty nose syndrome. Some studies had reported a $30 \%$ incidence of epiphora after medial maxillectomy. No complaints of persistent nasal crusting or epiphora in our study.

In our EPMM cases, one or two sutures at the incision site using 4-0 vicryl were performed withoutany adverse event like necrosis or detachment of inferior turbinate. It was difficult to examine the tumor recurrence through the inferior meatus in EPMM during the follow-up period because the mucosa of inferior meatus was preserved.

The main advantages of EPMM are extensive surgical exposure for all maxillary sinus walls without compromising the nasolacrimal duct and inferior turbinate. The mucoperiosteumover the canine fossa prevents ascending maxillary sinus disease as it acts as a primary barrier, is preserved in EPMM while it is the manipulated site in CLA. If there is no reluctance to sub labial incision, both approaches can be used for all benign maxillary tumors according to the surgeon's preference. However, based on our experiences, in this study, we would like to discuss the strengths and weaknesses of EPMM and CLA. The anterior wall of the maxillary sinus tumor is managed more efficiently by EPMM than CLA. On the contrary, the superomedial wall is relatively difficult to be manipulated by EPMM compared with CLA. Although the anteroinferior wall is also difficult to approach by both approaches, there is more chance of damage of anterior inferior alveolar nerve when drilling anteriorly in performing EPMM.

\section{Conclusion}

From these data, we concluded that EPMM is a useful approach for benign lesions of the entire maxillary sinus walls without lacrimal duct or inferior turbinate injury. The duration of facial paraesthesias after surgery was also significantly shorter than that of CLA.The recurrence rate is less in CLA when compared to EPMM. 


\section{References}

1. Bailey BJ, Calhoun KH, Friedman NR, Newlands SD, Vrabec JT. Atlas of Head and Neck Surgery-Otolaryngology. Philadelphia, Lippincott, Williams, and Wilkins(2001).

2. Kennedy DW (2001). Diseases of the Sinuses Diagnosis and Management. Hamilton, Ontario, BC Decker

3. Ungari C, Riccardi E et al. Management and treatment of sinonasal inverted papilloma. Ann Stomatol (Roma). 2016 Feb;6(3-4):87-90.

4. Sathananthar S, Nagaonkar S, et al. Canine fossa puncture and clearance of the maxillary sinus for the severely diseased maxillary sinus. Laryngoscope. 2005 Jun;115(6):1026-9.

5. Zhou B, Han DM et al. Intranasal endoscopic prelacrimal recess approach to the maxillary sinus. Chin Med J (Engl). 2013 Apr;126(7):1276-80.

6. Osguthorpe JD, Weisman RA. 'Medial maxillectomy' for lateral nasal wall neoplasms. Arch Otolaryngol Head Neck Surg. 1991 Jul;117(7): 751-6.

7. Morrissey DK, Wormald PJ, Psaltis AJ. Prelacrimal approach to the maxillary sinus. Int Forum Allergy Rhinol. 2016 Feb;6(2):214-8. 